\title{
Celestina: Documento bibliográfico (suplemento número 39)
}

\author{
Devid Paolini \\ The City College of New York
}

2515. ÁLVAREZ MORENO, Raúl, "Notas a la ilustración de un duelo: el suicidio de Melibea en los grabados antiguos de Celestina», eHumanista 35 (2016), 311-331.

Se estudia el patrón iconográfico del suicidio de Melibea señalando la posibilidad de que su realización se debió a la intención de los editores de dar una lectura moralizadora de la obra frente a su innata ambigüedad.

2516. BASTIANES, María, "Entrevista con Ángel Facio, director de teatro", Celestinesca 40 (2016), 229-242.

Una entrevista al director Ángel Facio acerca de su adaptación del clásico español que se estrenó en Colombia en 1979.

2517. BASTIANES, María, "De La Celestina de Rojas a la adaptación de Alejandro Casona. Un estudio comparativo», eHumanista 35 (2016), 238-256.

El trabajo presenta un análisis comparativo de la adaptación de LC que realizó Alejandro Casona en 1965 para la compañía Lope de Vega.

2518. CANET, José Luis, "La edición burgalesa de la Comedia de Calisto y Melibea: ¿manipulación lucrativa de su fecha de impresión?», eHumanista 35 (2016), 408-438.

El estudioso propone una fecha más tardía para el ejemplar de la CCM que se conserva en la Hispanic Society of America así como la pérdida de un cuadernillo al principio y el posible contenido de una hoja final (también perdida). 
2519. CANET, José Luis, "Giraldi Cinthio, la comedia y la Celestina», Studi giraldiani 3 (2017), 9-70.

Un análisis de las ideas expresadas por Giraldi Cinthio en su Discorso acerca de la comedia, la tragedia y $L C$. Todo parece indicar que nunca vio a un ejemplar de la obra maestra española.

2520. CANTALAPIEDRA EROSTARBE, Fernando, "Notas sobre El Manuscrito de Palacio II-1520, adiciones marginales y controversias filol gicas», Celestinesca 40 (2016), 9-52.

Un detenido estudio de los dos diferentes estadios del Manuscrito de Palacio, analizando, en particular, la mano del primer copista y las adiciones del segundo. Señala, al mismo tiempo, algunas posibles soluciones para algunos de los problemas todavía sin solución del primer acto: de Minerva con el can y la abuela de Calisto con el simio, hasta los huevos cocidos.

2521. CARMONA, Fernando \& Johanna VOLLMEYER, "Das sind ja unheimliche Spiele, die ihr treibt'. La Celestina en el expresionismo alemán», eHumanista 35 (2016), 332-350.

Un estudio de la adaptación libre de LC al alemán a cargo de Alfred Wolfenstein que se estrenó en teatro en 1928. En particular se centra en los cambios estéticos y temáticos del que fue objeto el género dramático durante el expresionismo alemán.

2522. CASAS AGUILAR, Anna, "Hacia una nueva subjetividad: La fig ra del padre en la novela sentimental y La Celestina», Celestinesca 40 (2016), 53-72.

Pleberio es una parodia de la figura del padre de las novelas sentimentales. Sin embargo, el padre de Melibea tiene una nueva subjetividad que lo aleja del clásico personaje paterno autoritario e imparcial para presentarlo como un ser más humano en relación con la muerte de su amada hija.

2523. GÓMEZ GOYZUETA, Ximena, «De viva y vieja voz: Celestina por sí misma», Celestinesca 40 (2016), 73-86.

Si por un lado el personaje de Celestina forma parte de la tradición misógina, por el otro el perspectivismo del diálogo celestinesco permite superar esa tradición presentando a una alcahueta consciente de sí misma y capaz de subvertir los defectos que le achacan a su favor. 
2524. LÓPEZ GONZÁLEZ, Luis F., «Voyeurism and Shame: The Pleasure of Looking and the Pleasure of Being Looked at in La Celestina», Celestinesca 40 (2016), 87-116.

Tras analizar la importancia de la mirada en $L C$, el artículo se detiene en el estudio de la interacción entre el voyeurismo y la vergüenza en el episodio de la unión sexual entre Pármeno y Areúsa y los dos encuentros amorosos de Calisto y Melibea.

2525. MARTÍ CALOCA, Ivette, «“Saltos de gozo infinitos’: Melibea como gran depredadora», eHumanista 35 (2016), 296-310.

Tras una breve reseña de los diferentes estudios que se han ocupado de las canciones de Lucrecia y Melibea en el acto XIX, la autora presenta su propio análisis de las octavillas que canta la criada: por un lado nos muestran a una Melibea desconcertante y fascinante al mismo tiempo, y por el otro se caracterizan por una ironía dramática sin par en la obra.

2526. MIAJA DE LA PEÑA, María Teresa, "Ex visu en La Celestina. Los personajes como reflejo de la mirada de los otros", eHumanista 35 (2016), 369-376.

El artículo se enfoca en la importancia del ver y mirar en la obra como elementos que relacionan entre sí los personajes y sus deseos.

2527. MIER, Laura, «Melibea, Plácida y Serafina: tres muertes violentas en el primer teatro clásico», Celestinesca 40 (2016), 117-134.

El trabajo analiza y compara el suicidio por amor del personaje femenino en tres obras escritas en años muy cercanos: LC de Rojas, la Égloga de Plácida y Vitoriano de Encina y la Comedia Serafina de Torres Naharro.

2528. MONTANER FRUTOS, Alberto y Eva LARA ALBEROLA, «La hechicería en $L C$ desde el estudio de la magia», en Grandes y pequeños de la literatura medieval y renacentista, ed. Emilio Blanco. Salamanca: SEMYR, 2016, 433-82.

Tras una revisión de las principales posturas de la crítica acerca de la presencia de la magia en $L C$, el artículo analiza la hechicería en la obra desde el punto de vista de la magia como disciplina en sí misma, lejos de una postura histórica-literaria que se ha seguido hasta el momento. 
2529. MONTERO, Ana Isabel, «Pues no la has tú visto como yo’: Scrutinizing and Resignifying the Beauty Myth in Celestina», eHumanista 35 (2016), 351-361.

Señala cómo la obra se aleja de los ideales estéticos de belleza y fealdad de la época y cómo Celestina muestra su naturaleza artificial al preparar y vender afeites y remendar hímenes.

2530. PADILLA CARMONA, Carles, "Precedentes clásicos del conjuro del acto tercero de La Celestina», eHumanista 36 (2017), 231-240.

El artículo presenta un análisis del conjuro de Celestina enfocándose, en particular, en el objeto mágico que emplea la vieja alcahueta: un hilado. Además de Lucano y Mena, otra posible fuente del pasaje sería el Satiricón de Petronio.

2531. PAOLINI, Devid, "Algunas observaciones sobre el problema de la génesis de Celestina», eHumanista 35 (2016), 362-368.

El artículo presenta algunas consideraciones sobre el dramatismo de $L C$ y la casi total ausencia de una tradición dramática en Castilla en la época y termina conjeturando la posibilidad de que un primer esbozo de la obra se haya gestado fuera de la península ibérica.

2532. PAOLINI, Devid, "De "viles acemileros» y «Minerva con el can»: una posible lectura", Revista de filología española 97.1 (2017), 205-214.

La breve nota intenta explicar el pasaje oscuro "Minerva con el can». La posible fuente podría ser el Novellino de Masuccio Salernitano.

2533. PEDROSA, José Manuel, «Cupido, Peropalo, Plutón y san Antonio de Padua: mito, rito e iconoclastia (entre La Celestina y Lope)", eHumanista 35 (2016), 475-494.

Un estudio del romance "Una estatua de Cupido» atribuido a Lope de Vega, cuyo tópico (el amante enfurecido que se enfada y se venga apedreando una estatua del dios del amor) se relaciona también con el conjuro a Plutón de $L C$.

2534. PRIETO DE LA IGLESIA, Remedios y Antonio SÁNCHEZ SÁNCHEZ-SERRANO, «Posibles razones por las que la Celestina fue considerada anónima durante los siglos XVI-XVIII y creación de Rojas a partir del XIX», Celestinesca 40 (2016), 135-158. 
El trabajo presenta un detenido análisis de los paratextos preliminares y se centra en la diferencia entre "auctor» (o sea el 'cedente') y "autor» ('componedor, refundidor y editor'). Todo eso con el objetivo de explicar el porqué $L C$ se consideró anónima durante los siglos XVI-XVIII y se atribuyó a Rojas a partir del siglo XIX.

2535. PRIETO DE LA IGLESIA, Remedios y Antonio SÁNCHEZ SÁNCHEZ-SERRANO, "Leyendo analíticamente la Celestina. Huellas en sus diálogos de la trama argumental de una comedia precedente», eHumanista 35 (2016), 377-407.

El estudio se enfoca en los diálogos de la CCM con el objetivo de señalar las diferentes huellas que permitirían reconstruir la trama original de lo que fue, in principio, una comedia humanística manuscrita (que luego Rojas amplió y empeoró).

2536. SAGUAR GARCÍA, Amaranta y Antonio CORTIJO OCAÑA, "La cuarta etapa de los estudios celestinescos», eHumanista 35 (2016), viii$\mathrm{xv}$.

Una breve introducción al monográfico dedicado a $L C$ en el volumen número 35 (2016) de la revista eHumanista. Todas las contribuciones se reseñan en este suplemento.

2537. SAGUAR GARCÍA, Amaranta, «La desaparición de la traducción italiana de Celestina del mercado editorial en la segunda mitad del siglo XVI», en Grandes y pequeños de la literatura medieval y renacentista, ed. Emilio Blanco. Salamanca: SEMYR, 2016, 625-642.

Estudia la trayectoria editorial y comercial de la traducción italiana de $L C$ y cómo las ediciones sucesivas afectaron a la materialidad del texto hasta su agotamiento y desaparición a mediados del siglo XvI.

2538. SÁNCHEZ Y SÁNCHEZ, Samuel, «Prince Juan and Calisto: Refle tions on a Historical Antecedent for a Literary Archetype», Celestinesca 40 (2016), 159-192.

Un estudio del contexto cultural en que se compuso $L C$ con el objetivo de señalar algunas de las posibles fuentes de la obra maestra. Entre estas, se propone a la vida amorosa y la muerte del primogénito de los Reyes Católicos como modelo para el personaje de Calisto. 
2539. TORREGROSA DÍAZ, José Antonio, "El texto de Celestina: hacia una vulgata editio», eHumanista 35 (2016), 257-276.

El estudio muestra algunas de las inexactitudes que todavía se recogen en las ediciones modernas de $L C$ e invita a la preparación de una vulgata editio de la obra que tenga en consideración los avances de la crítica textual de los últimos años.

2540. XIAO, Yang, "Reseña y análisis del estudio comparativo entre La Celestina e Historia del ala oeste», eHumanista 35 (2016), 277-295.

Un repaso de los cinco estudios que hasta ahora han analizado y comparado la obra china Historia del ala oeste con $L C$ señalando sus virtudes y defectos. El análisis llevado a cabo muestra la necesidad de volver a comparar las dos obras desde una nueva perspectiva.

2541. ZAFRA, Enriqueta, "Sexo en la ciudad: La Celestina y La Lozana para la clase del siglo XXI», eHumanista 36 (2017), 218-230.

Un acercamiento al contexto cultural de las dos obras mencionadas en el título con particular referencia a las costumbres y las leyes que se ocupaban de las prácticas sexuales de la época. 